\title{
A metabolomics approach to identify and quantify the phytochemicals in watermelons by quantitative ${ }^{1}$ HNMR
}

\author{
G. K. Jayaprakasha* and Bhimanagouda S. Patil* \\ Vegetable and Fruit Improvement Center, Department of Horticultural Sciences, \\ Texas A\&M University, 1500 Research Parkway, Suite A120, College Station, \\ TX 77845-2119, USA
}

*Corresponding authors emails: gkjp@tamu.edu; $\underline{\text { b-patil@ @tamu.edu }}$ 


\section{ABSTRACT}

Watermelon (Citrullus vulgaris) contains many health-promoting compounds, such as ascorbic acid, carotenoids, phenolic acids and amino acids including L-citrulline, arginine, and glutathione. Reported HPLC method for quantification of L-citrulline and sugars in watermelon involves extensive, time-consuming sample preparation, post-column color development and detection with fluorescence and refractive index detectors. The present study describes development of a method to identify and quantify amino acids and sugars simultaneously from watermelon samples using quantitative proton NMR. Lyophilized watermelon samples (30-50 mg) were extracted with deuterium oxide $\left(\mathrm{D}_{2} \mathrm{O}\right)$ by sonication and the centrifuged extract was directly used for quantification and identification with ${ }^{1} \mathrm{HNMR}$. An external coaxial insert

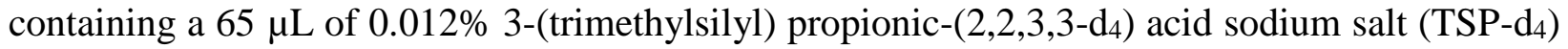
in $\mathrm{D}_{2} \mathrm{O}$ was used as a quantitative reference. The levels of L-citrulline and sugars were measured in less than $6 \mathrm{~min}$. This rapid quantitation method was validated for specificity, linearity, accuracy, precision, reproducibility, and robustness. The limit of detection for L-citrulline was $38 \mu \mathrm{g} / \mathrm{mL}$ and the limit of quantification was $71 \mu \mathrm{g} / \mathrm{mL}$; for sugars, the limits were $59-94 \mu \mathrm{g} / \mathrm{mL}$ and $120 \mu \mathrm{g} / \mathrm{mL}$, respectively. This method can be used widely for confirmation and rapid quantitation of multiple compounds in large number of biological or breeding samples for routine analysis.

Keywords: Citrullus vulgaris, L-Citrulline, Sugars, Amino acids, qNMR, Quantitation 


\section{Introduction}

Watermelon (Citrullus vulgaris) is an important fruit crop with an annual production of approximately 90 million tons. Watermelon is largely consumed as refreshing summer fruit throughout the world and also provides many health benefits [1]. The consumption of fruits and vegetables in appropriate quantities seems to be beneficial in prevention of cardiovascular disease [2, 3], cancer [4], ischemic stroke [5], pulmonary disease, cataracts, and hypertension [6], and can help improve bone health [7]. Watermelon provides a wide range of dietary antioxidants such as carotenoids (lycopene and $\beta$-carotene), polyphenolics, micronutrients, vitamins (A, B, C, and E) and specific amino acids (citrulline and arginine). Lycopene has demonstrated antioxidant activity and a potential role in prevention of prostate cancer [8, 9]. L-citrulline is a non-protein amino acid that was first identified from watermelon [10]. L-citrulline is emerged as an important amino acid both as a product of the NO cycle and as a precursor for arginine [11]. It is also an essential amino acid for young mammals and adults with trauma, burn injury, massive small bowel resection, and renal failure [12]. Conversion of L-citrulline to arginine by the enzyme peptidyl arginine deiminase liberates NO; peptidyl arginine deiminase also converts arginine back into L-citrulline [13].

Efforts to breed watermelon varieties with improved amounts of L-citrulline in combination with consumer-pleasing levels of sugar will require rapid methods for simultaneous quantification of these phytochemicals. However, standard methods have limited accuracy and require time-consuming separation and detection steps. For example, the reported spectrophotometric method for quantification of L-citrulline has limitations in terms of accuracy and detection levels. This method involves the reaction with oxime (3-hydroxyimino 2-butanone) in the presence of strong acids [14] to obtain a colored product. However, this reaction is not 
specific for L-citrulline. Other studies have reported HPLC methods for the determination of Lcitrulline and homocitrulline by post-column color development using o-phthalaldehyde and N(1-naphthyl)-ethylenediamine [15], but these treatments are tedious and also detection with visible light is less sensitive compared with detection in the ultraviolet region. Moreover, the resulting color may not remain stable during HPLC analysis. An additional study reported a precise RP-HPLC method for the simultaneous determination of twelve molecules participating in a metabolic cycle [16]. After pre-column derivatization with ortho phthalaldehyde containing 3-mercaptopropionic acid, the fluorescent derivatives were separated by gradient elution and detected using fluorescence detector [16] This method is sensitive and accurate, but will be tedious and protracted for the analysis of large numbers of samples.

Nuclear magnetic resonance (NMR) spectroscopy is a well-known analytical technique for elucidating the structure of small molecules and macromolecules [17]. ${ }^{1} \mathrm{H}$ NMR spectroscopy has been used for quantitative analysis since 1963 for determining the intra-molecular proton ratios in pure organic substances [18]. In natural products research, quantitative proton nuclear magnetic resonance (qHNMR) has emerged as one of the most reliable and suitable techniques for comprehensive qualitative and quantitative analysis. The main advantage of qNMR compared to other analytical methods is the primary ratio measurement, since the peak area in qNMR is proportional to the number of nuclei $\left(\mathrm{CH}, \mathrm{CH}_{2}\right.$, and $\left.\mathrm{CH}_{3}\right)$ giving rise to the signal. With qNMR, the quantitation of the compounds present in a complex sample can be performed in a single, rapid, non-destructive measurement. Sample preparation for qNMR is simple, non-tedious and the uncertainty in quantification is minimal. NMR spectroscopy has additional advantages, such as the ability to determine molecular structures from complex sample matrix and also possible to quantitatively analyze multiple metabolites simultaneously from a mixture. For example, 
nonselective ${ }^{1} \mathrm{H}$ NMR-based metabolomics and multivariate analysis by partial least-squares regression was used to obtain a model to evaluate sensory quality rankings of watermelon samples [19]. However, this paper did not describe the quantitation of L-citrulline and sugars from watermelon.

The main objective of the present study was to develop a simple and versatile quantitative NMR method for the simultaneous quantification of L-citrulline and sugars in watermelons.

\section{Materials and methods}

\subsection{Plant Materials}

Watermelon (C. vulgaris) varieties such as Petite Treat and Jamboree were harvested at Texas AgriLife Research Center (Uvalde, TX). Small and big watermelons of Petite Treat were also obtained from the local supermarket for comparison. Seeds were removed manually and the edible part was juiced, freeze-dried, and stored at $-20^{\circ} \mathrm{C}$ until analysis.

\subsection{Chemicals}

Solvents used for the analysis were all HPLC-grade and were obtained from Fisher Scientific (Houston, TX, USA). Ultrapure water (NANOpure, Barnstead, Dubuque, IA, USA) 18 $\mathrm{M} \Omega \mathrm{cm}$ was used for liquid chromatography. L-arginine and L-citrulline were purchased from Sigma-Aldrich, (St. Louis, MO, USA). Other chemicals and reagents used in this study were purchased form Fisher Scientific, (Somerville, NJ, USA). TSPd 4 (3-(trimethylsilyl) propionic acid- $\mathrm{D}_{4}$ sodium salt, 98 atom $\left.\% \mathrm{D}\right), \mathrm{D}_{2} \mathrm{O}(99.9$ atom $\% \mathrm{D})$ were purchased from Cambridge Isotope Laboratories Inc. (Tewksbury, MA, USA).

\subsection{Sample preparation}


For qNMR, HPLC and LC-MS analysis: To identify and quantify metabolites from watermelon samples, 3-4 fruits of each variety were juiced and lyophilized. A known amount (30-50 mg) of freeze-dried juice powder was taken in a 4-mL amber vial, and metabolites were extracted with $2 \mathrm{~mL}$ of deuterium oxide $\left(\mathrm{D}_{2} \mathrm{O}\right)$ by sonication for $1 \mathrm{~h}$ with occasional mixing. The sample was centrifuged for $15 \mathrm{~min}$ at $10,000 \mathrm{rpm}$ and reside was re-extracted with $500 \mu \mathrm{L}$ of $\mathrm{D}_{2} \mathrm{O}$ as mentioned above. The combined extracts were passed through a $0.45 \mu \mathrm{m}$ filter to remove insoluble particles and this sample was used for identification of metabolites by ${ }^{1} \mathrm{H}$ qNMR and LC-MS and sugars by HPLC.

References for NMR: ${ }^{1} \mathrm{H}$ NMR spectra were recorded for the 18 reference standards including amino acids, organic acids, and sugars listed in Table 1 for assignment of signals. The assignments were aided by comparison with chemical shift values in the literature [20,21]. Each amino acid was dissolved in $\mathrm{D}_{2} \mathrm{O}$ at a concentration of $2 \mathrm{mg} / \mathrm{mL}$ and $525 \mu \mathrm{L}$ was used along with the internal standard TSP-d $\mathrm{d}_{4}$ 1D ${ }^{1} \mathrm{H}$ NMR spectra of this mixture were also acquired for the cross validation and identification of each signal.

L-citrulline by HPLC: A known quantity (0.4-0.6 g) of freeze-dried watermelon powder was used for sample preparation according to our published protocols [22] with slight modifications. The samples were extracted with $10 \mathrm{~mL}$ of $\mathrm{MeOH}$ and $0.5 \mathrm{~mL}$ of $1 \mathrm{~N} \mathrm{HCl}$, by mixing and sonication (Cole-Parmer, IL, USA) for $30 \mathrm{~min}$. The extract was neutralized to $\mathrm{pH} 7$ with dilute $\mathrm{NaOH}$ and filtered through Whatman No. 1 paper to removed solids. For HPLC analysis, $1 \mathrm{~mL}$ was passed through a 0.22 micron membrane filter and injected into HPLC for quantification of L-citrulline. Extraction and analysis of all the samples were carried out in triplicates and averaged. The L-citrulline concentration was calculated on the basis of linear 
calibration functions and with regard to the dilution factor. The L-citrulline content was expressed as mg per $\mathrm{g}$ of freeze-dried watermelon sample.

\section{4. ${ }^{1}$ HNMR for quantification and identification of phytochemicals}

1D ${ }^{1} \mathrm{H}$ NMR spectra were obtained on an ECS-400 spectrometer (JEOL-USA, Peabody, MA, USA) composed of fully digitized circuitry including RF generator, NMR lock, and digital matrix shim, equipped with a z-field gradient unit, operating at $400 \mathrm{MHz} .1 \mathrm{D}{ }^{1} \mathrm{H}$ NMR spectra were acquired using a single pulse sequence with a $5 \mathrm{~mm}$ multinuclear inverse probe head and NM-ASC24 auto-sample changer. 1D ${ }^{1} \mathrm{H}$ NMR spectra were acquired using a single pulse sequence without water suppression using the following conditions: acquisition point 131,072, total transients 128 , relaxation delay $16 \mathrm{~s}$, number of scans 16 , and instrument calculated receiver gain automatically. Free induction decays were processed with line broadening of $0.2 \mathrm{~Hz}$ prior to Fourier transformation. Acquisition and processing of spectra were made with the Delta software version 4.3.6 (Windows NT). The spectrometer was locked on $\mathrm{D}_{2} \mathrm{O}$ and all spectra were acquired at $25^{\circ} \mathrm{C}$. The $1 \mathrm{D}{ }^{1} \mathrm{H}$ NMR spectra were recorded with the standard pulse sequence for presaturation of the water signal at $\delta 4.86 \mathrm{ppm}$, and the spectral width of $\delta 10 \mathrm{ppm}$. The spectra were recorded at different relaxation delays such as $2,4,8,12$, and $16 \mathrm{~s}$.

To confirm identification of unknown metabolites, spectra were obtained after addition of known amounts $(100 \mu \mathrm{L})$ of stock solution $(1 \mathrm{mM})$ of the authentic standard to the $425 \mu \mathrm{L}$ watermelon sample. For quantitative analysis, resonances were integrated manually in appropriate regions, the chemical shifts of all data were referenced to the IS resonance at 3.02, 3.98, 5.11, and 5.28 ppm for L-citrulline, fructose, glucose, and sucrose, respectively. According to the above parameters, the run time was $5.7 \mathrm{~min}$. The proton signals of TSP $(-0.11 \mathrm{ppm}, \mathrm{s})$ of 
IS were used for quantification. The purity of the analyte was calculated by the following formula [23],

$$
\text { Analyte }(\mathrm{x}) \text { concentration }=\frac{\mathrm{Ix} \cdot \mathrm{N}_{\mathrm{IS}} \cdot \mathrm{Mx} \cdot \mathrm{W}_{\mathrm{IS}} \cdot \text { Purity of IS }}{\mathrm{I}_{\mathrm{IS}} \cdot \mathrm{Nx} \cdot \mathrm{M}_{\mathrm{IS}} \cdot \mathrm{Wx}}
$$

Where I, N, M, W, and P are integral area, number of nuclei, molar mass, gravimetric weight and purity of analyte (x), and internal standard (IS) respectively.

\subsection{Peak assignment, quantitation and identification of phytochemicals.}

Four major watermelon phytochemicals were quantified by ${ }^{1} \mathrm{H}$ qNMR and identified by ${ }^{1} \mathrm{H}$ and ${ }^{13} \mathrm{CNMR}$ chemical shifts as well as peak multiplicity. These putative unique compounds were confirmed by spiking with authentic known standards. The remaining eleven signal assignments relied on published literature values [21, 24, 25], proton chemical shifts, and peak multiplicity for confirmation.

\subsection{Validation of quantitative ${ }^{1} H$ qNMR method}

The developed ${ }^{1} \mathrm{H}$ qNMR method was validated using calibration curves for precision, accuracy, repeatability, limit of detection (LOD), and limit of quantitation (LOQ).

Linearity and calibration curves. Accurately prepared standard solutions of L-citrulline, glucose, fructose, and sucrose at around $2 \mathrm{mg} / \mathrm{mL}$ in $\mathrm{D}_{2} \mathrm{O}$ were serially diluted to get 6 different concentrations and $525 \mu \mathrm{L}$ of each standard was used for NMR measurement along with $65 \mu \mathrm{L}$ of TSP- $\mathrm{d}_{4}$. Calibration curves were constructed by plotting the integral areas of each standard obtained by ${ }^{1} \mathrm{H}$ qNMR versus the actual concentration. 
Detection limits. Limit of detection (LOD) is the lowest concentration of a phytochemical that can be detected; limit of quantitation (LOQ) is the lowest concentration of a phytochemical can be accurately and precisely quantified. For each phytochemical, both LOD and LOQ were determined by serial dilution of stock solution as described above.

Precision, specificity, and stability: Three samples of watermelon were chosen to measure in 10 replicates for the precision assay at different time points $(0,24$, and $48 \mathrm{~h})$. The specificity and selectivity of the proposed method was evaluated by recording the ${ }^{1} \mathrm{H}$ NMR spectra of the known amount watermelon sample $(400 \mu \mathrm{L})$ mixed with $125 \mu \mathrm{L}$ of glucose, fructose, sucrose, or L-citrulline to see the enhancement of the respective signal. The absence of overlapping signal was used for quantification. The stability study was carried out by detecting the same sample at different time points $(0,12,24,36$, and $48 \mathrm{~h})$ during storage at $25^{\circ} \mathrm{C}$.

Recovery study. The recovery of L-citrulline was determined for three watermelon samples (30 mg), which were spiked with $100 \mu \mathrm{L}$ of of L-citrulline at three concentrations $(5,10$, or $20 \mathrm{mg} / \mathrm{mL}$ ). Three replicates of each sample were extracted as mentioned in the sample preparation step and injected into the HPLC system. The total amount of L-citrulline was calculated from the calibration curve, and the extraction recovery was calculated by the following equation: Recovery $=[$ (amount determined in spiked samples $) /$ amount expected $] \times$ 100

\subsection{Quantification of phytochemicals by HPLC}

L-citrulline. The HPLC analysis was carried out using the Agilent 1200 Series, (Foster City, CA, USA) which consists of degasser, quaternary pump, auto-samplers, column oven, and photodiode array detector. The column temperature was maintained at $35^{\circ} \mathrm{C}$ and detection was 
performed at $210 \mathrm{~nm}$. The separation of L-citrulline was performed on Gemini C-18, $3 \mu \mathrm{m}$ particle size, $250 \mathrm{~mm} \times 4.6 \mathrm{~mm}$ (Phenomenex, Torrance, CA, USA) using $0.03 \mathrm{mM}$ phosphoric acid with a flow rate of $0.7 \mathrm{~mL} / \mathrm{min}$. ChemStation software was used for the quantification of Lcitrulline. All the extracts were filtered through 0.45 micron filters and $5 \mu \mathrm{L}$ was injected into the HPLC.

Sugar measurement. The $\mathrm{D}_{2} \mathrm{O}$ extracts prepared earlier were used in the determination of individual sugar content. A $20-\mu \mathrm{L}$ sample was injected into the HPLC system consisting of a binary pump, autosampler, refractive index detector (Perkin Elmer LC 200 Series, Norwalk, Conn., USA), and Rezex RNM-carbohydrate Na+ (8\%), (300 x $7.8 \mathrm{~mm})$ column with a guard column Carbo-Ca, (4x3 mm ID) (Phenomenex, Inc. Torrance, CA, USA). Nanopure water was used as a mobile phase at a flow rate of $0.5 \mathrm{~mL} / \mathrm{min}$ and the column temperature was maintained at $90^{\circ} \mathrm{C}$. Sugar concentrations were calculated using standard curves of sucrose, glucose, and fructose.

\subsection{High-resolution mass spectrometry (HR-MS)}

The three watermelon samples were analyzed by ultra-high performance liquid chromatography-time of flight-mass spectrometry (LC-QTOF-MS) (maXis impact, Bruker Daltonics, Billerica, MA). The separation was performed on a Kinetex C18 column $(1.7 \mu \mathrm{m}, 100$ $\times 2.1 \mathrm{~mm}$; Phenomenex, Torrance, CA, USA). The column was maintained at $50^{\circ} \mathrm{C}$ with a flow rate of $0.2 \mathrm{~mL} / \mathrm{min}$. The mobile phase consisted of: (A) water with $0.1 \%$ formic acid, and (B) acetonitrile. The gradient was as follows: isocratic run from 0 to 2 min $100 \% \mathrm{~A}$, gradient elution from $100-15 \%$ A for 2 to 9 min, $15-100 \%$ A from 9-10 min, isocratic $100 \%$ A for $10-11 \mathrm{~min}$. The column was equilibrated for 2 min before the next injection. Mass spectral analyses were 
performed using the ESI-Q-TOF mass spectrometer equipped with an electrospray ionization source in positive ion mode. MS experiments were carried out on a Bruker MaXis HR-Q-TOF mass spectrometer under the following conditions: ionization mode ESI (+); MS scan range 50$1000 \mathrm{~m} / \mathrm{z}$; end plate offset-500 V; capillary $-3000 \mathrm{~V}$, nebulizer gas $\left(\mathrm{N}_{2}\right) 0.4$ bar; dry gas $\left(\mathrm{N}_{2}\right) 4$ L/min; dry temperature: $180^{\circ} \mathrm{C}$; ion transfer conditions funnel RF: $200 \mathrm{Vpp}$; multiple RF: 200 Vpp; quadruple low mass 55 m/z; collision energy 5.0 eV; collision RF $600 \mathrm{Vpp}$; ion cooler RF 50-250 Vpp ramping; transfer time $121 \mu \mathrm{s}$; pre-pulse storage time $1 \mu \mathrm{s}$. Calibration was done before each run through a loop injector of $20 \mu \mathrm{L}$ of $10 \mathrm{mM}$ sodium formate.

\subsection{Statistical analysis}

All the experiments were conducted in triplicate and the analyses were performed in duplicate for each sample. Results are expressed as mean \pm standard error. ANOVA was performed to determine the variation for activity studies and data was analyzed by Tukey's posttest analysis using Graph Pad prism software version-5.00.288.

\section{Results and Discussion}

\subsection{Experimental conditions for $q^{l} H N M R$}

In a continuation of our earlier research on extraction efficiency of various phytochemicals from fruits and vegetables [22, 26-31], we conducted water / $\mathrm{D}_{2} \mathrm{O}$ extraction for lyophilized watermelon samples. After optimizing extraction time and solvent ratio, we processed three different watermelon samples. The TSP- $\mathrm{d}_{4}$ concentration in the capillary tube was pre-calibrated using a separate standard solution. Sufficiently long (12 s) relaxation delay 
was used to ensure full recovery of magnetization from sample and internal reference (TSP- $\left.\mathrm{d}_{4}\right)$ signals to equilibrium needed for the accurate quantification.

\subsection{Assignment of proton signals}

The $1 \mathrm{D}{ }^{1} \mathrm{H}$ NMR spectra were recorded with a standard single-pulse experiment with spectral width of $10 \mathrm{ppm}$. Data were collected into 130,000 data points after 16 scans plus 4 dummy scans. The acquisition time was $5.7 \mathrm{~min}$ and the relaxation delay was $12 \mathrm{~s}$. Table 1 summarizes the assignment of proton signals of 15 compounds used for identification of phytochemicals from watermelon samples. First, the signals of individual compounds were assigned using reference compounds, which were measured in parallel. L-citrulline exhibited four signals at $\delta 1.48(\mathrm{~m}, 2 \mathrm{H}), 1.78(\mathrm{~m}, 2 \mathrm{H}), 3.05(\mathrm{t}, 2 \mathrm{H})$, and $3.68(\mathrm{t}, 1 \mathrm{H})$, which belong to the H-4, 3, 5, and 2 positions respectively (Fig. 1). In addition, 14 different compounds including eight amino acids, three sugars, and three organic acids were used for comparison and validation of our NMR spectral assignments, as listed in Table 1 and Fig. S1. Three sugar signals were observed in the region between $\delta 3.00$ to $5.50 \mathrm{ppm}$ (Fig. 1). Sucrose was the minor non-reducing sugar in watermelon having resonances at $\delta 5.3(\mathrm{~d}), 4.1(\mathrm{~d}), 3.92(\mathrm{t}), 3.7(\mathrm{dd}), 3.65(\mathrm{t}), 3.45(\mathrm{dd})$, and 3.35 (t). Major signals belonging to monosaccharides (reducing sugar) including fructose, and glucose, resonated at $\delta 5.1(\mathrm{~d}), 4.51(\mathrm{~d}), 3.98(\mathrm{~d}), 3.88(\mathrm{dd}), 3.77(\mathrm{dd}), 3.67(\mathrm{dd}), 3.59(\mathrm{dd})$, $3.43(\mathrm{dd}), 3.3(\mathrm{dd})$, and $3.11(\mathrm{t})$. The specificity and selectivity of the ${ }^{1} \mathrm{H}$ NMR method was proven by the absence of overlaps of at least one signal from each analyte, solvent, and internal standard. Fig. 2 depicts the overlay of ${ }^{1} \mathrm{H}$ NMR spectra of watermelon samples spiked with glucose, fructose, sucrose, and L-citrulline. The non-overlapped spiked signals, such as $\delta 3.11$, 3.98, 5.3, and 3.05 were used for quantification of glucose, fructose, sucrose, and L-citrulline, respectively. 
1D ${ }^{13} \mathrm{C}$ decoupled NMR was used for verification of identified components in watermelon samples. The data collected comprised 32,000 points after 16,384 scans. In Fig. 3, a typical ${ }^{13} \mathrm{C}$ NMR spectrum of a watermelon sample is overlaid with standard L-citrulline. All Lcitrulline carbons signals were assigned and matched the standard signals. In addition, the three sugars present in the watermelon samples were confirmed by comparing ${ }^{13} \mathrm{C}$ DEPT-135 signals (Fig. 4). The unique chemical shifts are associated with the various carbons. The corresponding signals matched the standard signals, providing unambiguous identification of specific sugars and health-promoting compounds in watermelons. Considering the simple sample preparation and rapid simultaneous analysis of L-citrulline and sugars, the developed method will be useful for plant breeders to develop elite varieties with enhanced quality parameters such as higher levels of L-citrulline and sugar.

Development of a reliable, rapid, and accurate method for the analysis of phytochemicals will provide essential information to assess the quality of foods for nutritional and regulatory purposes. The currently available technique involves the separation of L-citrulline using precolumn derivatization and GC-MS methods [32, 33]. Many researchers use reversed-phase HPLC with precolumn derivatization. Typical reagents for pre-column derivatization are phenyl isothiocyanate (PITC), O-phthalaldehyde, 9-fluorenylmethyl-chloroformate (FMOC-Cl), 1fluoro-2,4-dinitrobenzene, 1-fluoro-2,4-dinitrophenyl-5-L-alanine amide, and dansyl-chloride [34]. Each of these reagents has particular advantages and limitations. Only PITC and $O$ phthalaldehyde are widely used for the analysis of amino acids, including L-citrulline. Recently, we optimized and developed a simple and rapid HPLC-UV method for the quantification of Lcitrulline without concentration, drying, and derivatization using a Gemini $\mathrm{C}_{18}$ column [22].

\subsection{Validation of the ${ }^{1} H$ qNMR method}


Linearity. Linearity was verified by preparing standard solutions at six concentrations for four selected phytochemicals. The quantitative analysis of individual compounds does not strictly require regression equations for each phytochemical, since the content of the phytochemical is strictly proportional to the integral area of the proton signal in the qNMR spectrum. However, depending on the concentrations of each phytochemical, the accuracy of this method can be determined by establishing calibration curves for each compound. Regression equations (Table 2; Fig. S1) were prepared to determine the levels of phytochemicals in different varieties of watermelon samples using qNMR. Calibration curves from three independent spectra were obtained for six concentrations of L-citrulline, sucrose, glucose, and fructose. The correlation coefficients $\left(\mathrm{R}^{2}\right)$ of the four compounds in the present study were found to be $>0.97$ (Table 2). Higher $\mathrm{R}^{2}$ values indicate a good linearity response within the concentration range studied (Fig. S1). Linearity concentrations for watermelon phytochemicals were obtained by serial dilution of the standard solution from $1.97-0.071 \mathrm{mg} / \mathrm{mL}$, with high reproducibility and accuracy. The estimated LOD for the phytochemicals in this study ranged from $38-94 \mu \mathrm{g} / \mathrm{mL}$ (Table 2).

Precision, specificity and stability. The precision of the qHNMR method was evaluated by measuring 10 replicates of three watermelon samples. The relative standard deviation (RSD) for L-citrulline was found to be $<7 \%$ indicating good precision. As shown in Fig S2, the baseline was flat, signals for all quantified metabolite were well resolved, and the line shapes for Lcitrulline signals were sharp, which demonstrates that the quantification of L-citrulline is precise. Stability testing is important for estimating the allowed time span between sample preparation and sample analysis. Watermelon samples are rich in sugars, so it is important to determine the time point when large number of samples should be analyzed during the harvesting session. This 
was assessed by analyzing the same sample solution for two days at 12 -h intervals. The sample solution was found to be stable during the tested period at $25^{\circ} \mathrm{C}$ for up to $48 \mathrm{~h}$ (Fig.6). The RSD value was within $8 \%$.

Recovery and robustness. The recovery and accuracy of the developed method were determined based on the agreement between the theoretical value and the measured experimental value. A recovery study was performed to verify the yield of extraction and quantification of Lcitrulline using qNMR. The data in Table 3 demonstrated good recovery of L-citrulline, in excellent agreement with our method for sample preparation in terms of recovery values. Fig. S2 shows the stepwise increase in L-citrulline signals in qNMR as spiking rate increased from 100 to $400 \mu \mathrm{L}$. The recovery value is given by the ratio of mean integral peak area obtained by direct analysis of L-citrulline standards and watermelon samples containing known concentrations of L-citrulline. The mean recovery of the L-citrulline from watermelon was found to be 101.7 to $109.2 \%$, reflecting the reliability and accuracy of the method, which seems to suggest our developed method can be used for quantification of L-citrulline from watermelon.

To evaluate the robustness of the method, acquisition parameters were investigated stepwise in wide ranges including acquisition time, relaxation delay, and scan numbers. We observed $<7 \%$ RSD in the ${ }^{1} \mathrm{H}$ qNMR and HPLC method. Most of the parameters did not have significant effects on the accuracy of the method within their evaluated ranges. For example, a $5 \%$ change in pulse length did not cause a variation in quantification. However, different relaxation delays produced an error in quantification due to incomplete relaxation of longitudinal magnetization [23]. Herein, we tried different relaxation delays, from 4 to 64 s (Fig. S3) and observed that a relaxation delay of more than $8 \mathrm{~s}$ was sufficient to get satisfactory results. These 
data demonstrated that the developed method is precise, accurate, and sensitive enough for simultaneous quantitative determination of these phytochemicals from watermelon samples.

\subsection{Quantification of phytochemicals in watermelon samples by ${ }^{1} \mathrm{H} q \mathrm{qMR}$.}

The concentration of L-citrulline $(\mathrm{mg} / \mathrm{g})$ was determined in different varieties of watermelons by ${ }^{1} \mathrm{H}$ qNMR and HPLC (Table 4). In the present study, we compared small and big melons obtained from TAMU AgriLife experimental station and a commercial source. Among small melons, commercial varieties showed significantly higher L-citrulline $(24.22 \pm 1.07 \mathrm{mg} / \mathrm{g})$ than TAMU melons, whereas in case of big melons, L-citrulline was higher in TAMU $(22.59 \pm$ $1.65 \mathrm{mg} / \mathrm{mL}$ ) than commercial melons. The L-citrulline showed a well-separated peak in the Gemini C-18 column (Fig S3). The identification of L-citrulline was determined by relative retention times of standard and/or by spiking with standard. L-citrulline contents in different varieties of small watermelon samples varied between $14.39 \pm 1.89$ to $24.37 \pm 1.09 \mathrm{mg} / \mathrm{g}$ whereas in big melons it varied from $16.98 \pm 0.21$ to $22.37 \pm 1.94 \mathrm{mg} / \mathrm{g}$. The levels of L-citrulline were comparable to reported values from our group [22] and elsewhere [32].

Table 5 presents the individual sugar levels determined by NMR and HPLC in 14 different watermelon samples. No significant differences were observed in most of the samples analyzed for glucose and fructose in both the methods, except one sample from a commercial Petite Treat watermelon had higher levels of glucose $(178 \pm 5.5 \mathrm{mg} / \mathrm{g})$ and fructose $(145.77 \pm 4.4$ $\mathrm{mg} / \mathrm{g}$ ) analyzed by HPLC. For sucrose quantification, four watermelon samples had significantly higher levels $(105.32 \pm 5.7,46.12 \pm 3.9,222.85 \pm 6.5$, and $244.88 \pm 6.1 \mathrm{mg} / \mathrm{g})$ by the NMR method as compared with the HPLC method $(94.9 \pm 3,30.74 \pm 3,205 \pm 3.6$, and $222.72 \pm 6.8 \mathrm{mg} / \mathrm{g}$ ) and one 
watermelon sample has visa versa. There is no significant differences were observed in remaining sample. Petite Treat small melons from TAMU had the highest levels of total sugars (813.55 mg/g) whereas big melons from commercial source had the lowest levels $(285.14 \mathrm{mg} / \mathrm{g})$. A similar trend was reported by Lee et al. [35] reported sugar levels in 39 watermelons in the range of 3.6 to $11 \%$ on a fresh weight basis. The high fructose content was important when screening lines in breeding populations, as the calculated sweetness value provides one criterion for estimating the palatability [36]. In the present study, four small watermelons and two big watermelons had $>40 \%$ fructose content (Table 5) with respect to total sugars. Existing methods for the analysis of sugars involve the conversion of carboxylic or hydroxyl groups to volatile derivatives for GC estimation [32]. Previous methods may provide appropriate concentrations, but they are tedious and time consuming, involving more unit operations and possibilities to produce experimental errors. In the present study, identification and quantification of L-citrulline and sugars were conducted accurately, simultaneously, and rapidly.

\subsection{Identification of minor metabolites}

Identification of phytochemicals and metabolic profiling is an emerging area in analytical chemistry exemplified by the fusion of analytical metabolite measurements. The present study involves metabolite profiling based on ${ }^{1} \mathrm{H}$ NMR (Fig. 6). The ${ }^{1} \mathrm{H}$ NMR spectrum of a watermelon sample is complex because of the presence of a large quantity of sugars in the

aliphatic region $(\delta 3-5 \mathrm{ppm})$. The intensity of a particular signal in the ${ }^{1} \mathrm{H}$ NMR spectrum of a watermelon sample is proportional to the number of nuclei that contribute to the signal. Here, we identified 18 metabolites on the basis of comprehensive analyses of the NMR spectra (Table 1 and Fig 6). Some of these metabolites were reported by Lucksanporn et al., [19]; however, the 
present study describes the quantitation of four major compounds along with identification of fourteen compounds. Quantitative NMR has been exploited for the analysis of individual components in natural product mixtures. The developed method can be used to measure the levels of certain metabolites quantitatively in a watermelon sample, within 6 min.

\subsection{Confirmation of major metabolites by HR-MS.}

Despite the fact that some polar compounds are present at high concentrations, identification of certain compounds along with minor amino acids by ${ }^{1} \mathrm{H}$ NMR spectroscopy is challenging. To further confirm these compounds, we used tandem LC-HR-MS. Fig. 7 presents the high-resolution mass spectra of four compounds: glucose, fructose, sucrose, and L-citrulline with molecular ions of 203.0534 [M+Na], 203.0528 [M+Na], 325.1179 [M+Na], and 176.1023 $[\mathrm{M}+1]$ respectively. All precursor and product ion masses exhibited accurate mass errors below $10 \mathrm{ppm}$. The molecules having molecular weights within a specified tolerance range relative to the unknown molecular weight were retrieved from databases as putative identifications.

In summary, a simple qNMR method for the determination of L-citrulline and three sugars in watermelon samples was developed and validated for the first time. Using this method, watermelons can be analyzed directly without extensive sample preparation. The identities of the targeted compounds were further confirmed by mass spectral analysis. The developed method was compared with the standard existing HPLC method and the values were found to be comparable. The method is well validated for linearity, precision, reproducibility, and stability Therefore, the present simple method can be used for the routine analysis of L-citrulline and sugars in commercial and biological samples. The $\mathrm{q}^{1} \mathrm{HNMR}$ method is independence of physical 
properties such as UV absorption. To the best of our knowledge, this is the first report of a qNMR method for the quantitation of phytochemicals from watermelon samples.

\section{Acknowledgements}

This study was supported by United States Department of Agriculture grant Designing Foods for Health through the Vegetable \& Fruit Improvement Center 2010-34402-20875 and State funding 2013-121277 VFIC-TX state appropriation.

\section{Appendix A. Supplementary data}

Supplementary data associated with this article can be found in Fig. S1 - S4.

\section{References}

[1] A. Rahmat, R. Rosli, S. Endrini, H. Abdullah, Antiproliferative Activity of Pure Lycopene Compared to Both Extracted Lycopene and Juices from Watermelon (Citrullus vulgaris) and Papaya (Caricapapaya) on Human Breast and Liver Cancer Cell Lines, Journal of Medical Sciences, 2 (2002) 55.

[2] S. Liu, J.E. Manson, I.M. Lee, S.R. Cole, C.H. Hennekens, W.C. Willett, J.E. Buring, Fruit and vegetable intake and risk of cardiovascular disease: the Women's Health Study, Am J Clin Nutr, 72 (2000) 922-928.

[3] L.A. Bazzano, J. He, L.G. Ogden, C.M. Loria, S. Vupputuri, L. Myers, P.K. Whelton, Fruit and vegetable intake and risk of cardiovascular disease in US adults: the first National Health and Nutrition Examination Survey Epidemiologic Follow-up Study, Am J Clin Nutr, 76 (2002) 93-99. 
[4] M.K. Campbell, W. Demark-Wahnefried, M. Symons, W.D. Kalsbeek, J. Dodds, A. Cowan, B. Jackson, B. Motsinger, K. Hoben, J. Lashley, S. Demissie, J.W. McClelland, Fruit and vegetable consumption and prevention of cancer: the Black Churches United for Better Health project, Am J Public Health, 89 (1999) 1390-1396.

[5] K.J. Joshipura, A. Ascherio, J.E. Manson, M.J. Stampfer, E.B. Rimm, F.E. Speizer, C.H. Hennekens, D. Spiegelman, W.C. Willett, Fruit and Vegetable Intake in Relation to Risk of Ischemic Stroke, JAMA, 282 (1999) 1233-1239.

[6] M.A.S. Van Duyn, E. Pivonka, Overview of the Health Benefits of Fruit and Vegetable Consumption for the Dietetics Professional: Selected Literature, Journal of the American Dietetic Association, 100 (2000) 1511-1521.

[7] S.A. New, S.P. Robins, M. Campbell, J. Martin, M. Garton, C. Bolton-Smith, D. Grubb, S. Lee, D. Reid, Dietary influences on bone mass and bone metabolism: further evidence of a positive link between fruit and vegetable consumption and bone health?, 71 (2000) 14-151.

[8] M. Li, Q. Wang, X. Zhang, X. Chen, J. Li, T. Ou, X. Cui, UP-1.136: Study of Lycopene Decrease PSA in Patients of Prostate Cancer, Urology, 74 (2009) S213-S213.

[9] P. Perkins-Veazie, J.K. Collins, Flesh quality and lycopene stability of fresh-cut watermelon, Postharvest Biology and Technology, 31 (2004) 159-166.

[10] R. Kasting, C. Delwiche, Ornithine, Citrulline, and Arginine Metabolism in Watermelon Seedlings, Plant physiology, 33 (1958) 350.

[11] M.J. Romero, D.H. Platt, R.B. Caldwell, R.W. Caldwell, Therapeutic use of citrulline in cardiovascular disease, Cardiovasc Drug Rev, 24 (2006) 275-290. 
[12] J.K. Collins, G. Wu, P. Perkins-Veazie, K. Spears, P.L. Claypool, R.A. Baker, B.A. Clevidence, Watermelon consumption increases plasma arginine concentrations in adults, Nutrition, 23 (2007) 261-266.

[13] R. Nissinen, L. Paimela, H. Julkunen, P.J. Tienari, M. Leirisalo-Repo, T. Palosuo, O. Vaarala, Peptidylarginine deiminase, the arginine to citrulline converting enzyme, is frequently recognized by sera of patients with rheumatoid arthritis, systemic lupus erythematosus and primary Sjögren syndrome, Scandinavian journal of rheumatology, 32 (2003) 337-342.

[14] K. Lorentz, H. Koch, Bestimmung von Ornithin-Carbamyl-Transferase mittels FEARONReaktion, Z. Klin. Chem. Klin. Biochem, 9 (1971) 215-219.

[15] I. Koshiishi, Y. Kobori, T. Imanari, Determination of citrulline and homocitrulline by highperformance liquid chromatography with post-column derivatization, Journal of Chromatography B: Biomedical Sciences and Applications, 532 (1990) 37-43.

[16] P. Markowski, I. Baranowska, J. Baranowski, Simultaneous determination of 1-arginine and 12 molecules participating in its metabolic cycle by gradient RP-HPLC method: Application to human urine samples, Analytica Chimica Acta, 605 (2007) 205-217.

[17] D.S. Wishart, Quantitative metabolomics using NMR, TrAC Trends in Analytical Chemistry, 27 (2008) 228-237.

[18] J. Jungnickel, J. Forbes, Quantitative Measurement of Hydrogen Types by Intergrated Nuclear Magnetic Resonance Intensities, Analytical Chemistry, 35 (1963) 938-942.

[19] L. Tarachiwin, O. Masako, E. Fukusaki, Quality Evaluation and Prediction of Citrullus lanatus by $1 \mathrm{H}$ NMR-Based Metabolomics and Multivariate Analysis, Journal of Agricultural and Food Chemistry, 56 (2008) 5827-5835. 
[20] E. Pretsch, T. Clerc, J. Seibl, W. Simon, Tables of spectral data for structure determination of organic compounds, Springer Science \& Business Media2013.

[21] L.I. Nord, P. Vaag, J.Ø. Duus, Quantification of organic and amino acids in beer by $1 \mathrm{H}$ NMR spectroscopy, Analytical chemistry, 76 (2004) 4790-4798.

[22] G.K. Jayaprakasha, K.N. Chidambara Murthy, B.S. Patil, Rapid HPLC-UV method for quantification of L-citrulline in watermelon and its potential role on smooth muscle relaxation markers, Food Chemistry, 127 (2011) 240-248.

[23] S.K. Bharti, R. Roy, Quantitative 1H NMR spectroscopy, TrAC Trends in Analytical Chemistry, 35 (2012) 5-26.

[24] S.K. Bharti, N. Sinha, B.S. Joshi, S.K. Mandal, R. Roy, C.L. Khetrapal, Improved quantification from 1H-NMR spectra using reduced repetition times, Metabolomics, 4 (2008) $367-376$.

[25] G. Nagana Gowda, Y.N. Gowda, D. Raftery, Expanding the Limits of Human Blood Metabolite Quantitation Using NMR Spectroscopy, Analytical chemistry, 87 (2014) 706-715.

[26] G. Jayaprakasha, R. Singh, K. Sakariah, Antioxidant activity of grape seed (Vitis vinifera) extracts on peroxidation models in vitro, Food Chemistry, 73 (2001) 285-290.

[27] G.K. Jayaprakasha, B.S. Jena, K.K. Sakariah, An improved HPLC method for the determination of organic acids in leaves, pulp, fruits and rinds of Garcinia, Journal of AOAC International, 86 (2003) 1003-1007, PMID: 14632411.

[28] A. Vikram, G.K. Jayaprakasha, B.S. Patil, Simultaneous determination of citrus limonoid aglycones and glucosides by high performance liquid chromatography, Analytica Chimica Acta, 590 (2007) 180-186, PMID: 17448343. 
[29] G.K. Jayaprakasha, B. Girennavar, B. Patil, S, Radical scavenging activities of rio red grapefruits and sour orange fruit extracts in different in vitro model systems, Bioresource Technology, 99 (2008) 4484-4494.

[30] G.K. Jayaprakasha, B.S. Patil, Extraction and Purification of Bioactive Ingredients from Natural Products, in: D.H. Vattem, M. Vatsala (Eds.) Functional Foods, Nutraceuticals and Natural Products, DEStech Publications, Lancaster, PA, 2015, pp. 153-174.

[31] H. Bae, G.K. Jayaprakasha, J. Jifon, B.S. Patil, Extraction efficiency and validation of an HPLC method for flavonoid analysis in peppers, Food Chem., 130 (2012) 751-758.

[32] A.M. Rimando, P.M. Perkins-Veazie, Determination of citrulline in watermelon rind, Journal of Chromatography A, 1078 (2005) 196-200.

[33] P. Husék, Rapid derivatization and gas chromatographic determination of amino acids, J. Chromatogr. , 552 (1991) 289-299.

[34] G. Sarwar, H.G. Botting, Evaluation of liquid chromatographic analysis of nutritionally important amino acids in foods and physiological samples, Journal of chromatography, 615 (1993) 1-22.

[35] S.J. Lee, J.S. Shin, K.W. Park, Y.P. Hong, Detection of genetic diversity using RAPD-PCR and sugar analysis in watermelon [Citrullus lanantus (Thunb.) Mansf.] germplasm, Theoret. Appl. Genetics, 92 (1996) 719-725.

[36] G. Elmstrom, P. Davis, K. Munroe, Sugars in maturing fruit of watermelon cultivars, HortScience, 15 (1980). 


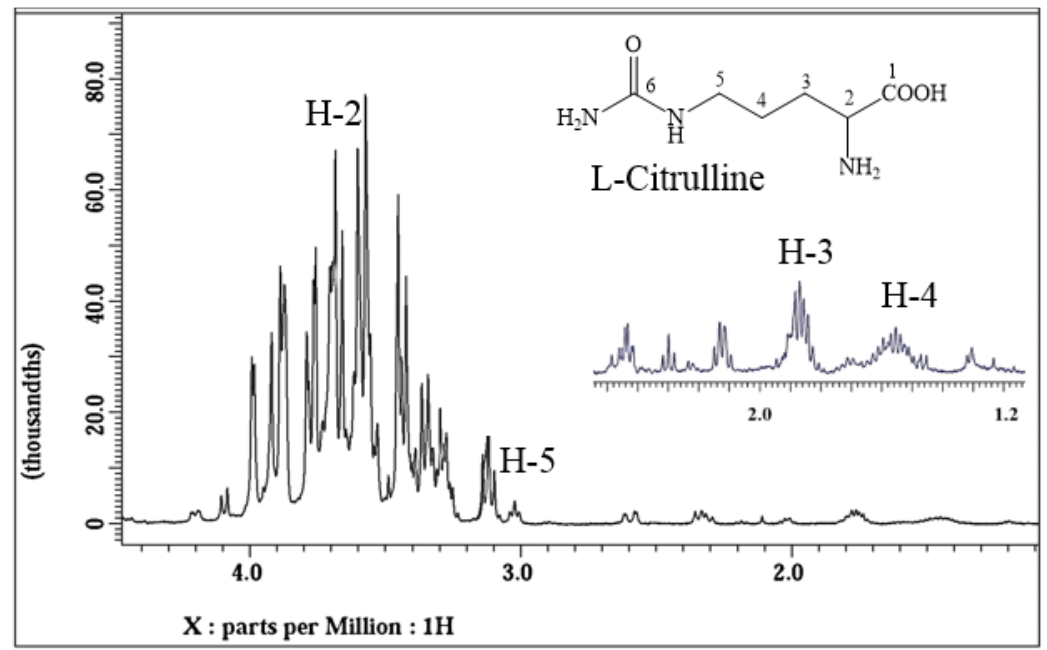

Fig. 1. Typical ${ }^{1} \mathrm{H}$ NMR spectrum of a watermelon sample recorded at $400 \mathrm{MHz}$ in $\mathrm{D}_{2} \mathrm{O}$. Lcitrulline proton signals were assigned to respective signals in both spectra. Thirty mg of freeze-dried watermelon sample was extracted with $1 \mathrm{~mL}$ of $\mathrm{D}_{2} \mathrm{O}$ by vortexing for $1 \mathrm{~min}$ and sonication for $30 \mathrm{~min}$. The extract was filtered and a $525 \mu \mathrm{L}$ aliquot was transferred into 5-mm NMR tubes for NMR measurements. An external glass stem coaxial insert (OD $2 \mathrm{~mm}$ ) containing $65 \mu \mathrm{L}$ of $0.012 \%$ TSP solution in $\mathrm{D}_{2} \mathrm{O}$ was used for quantitation. 


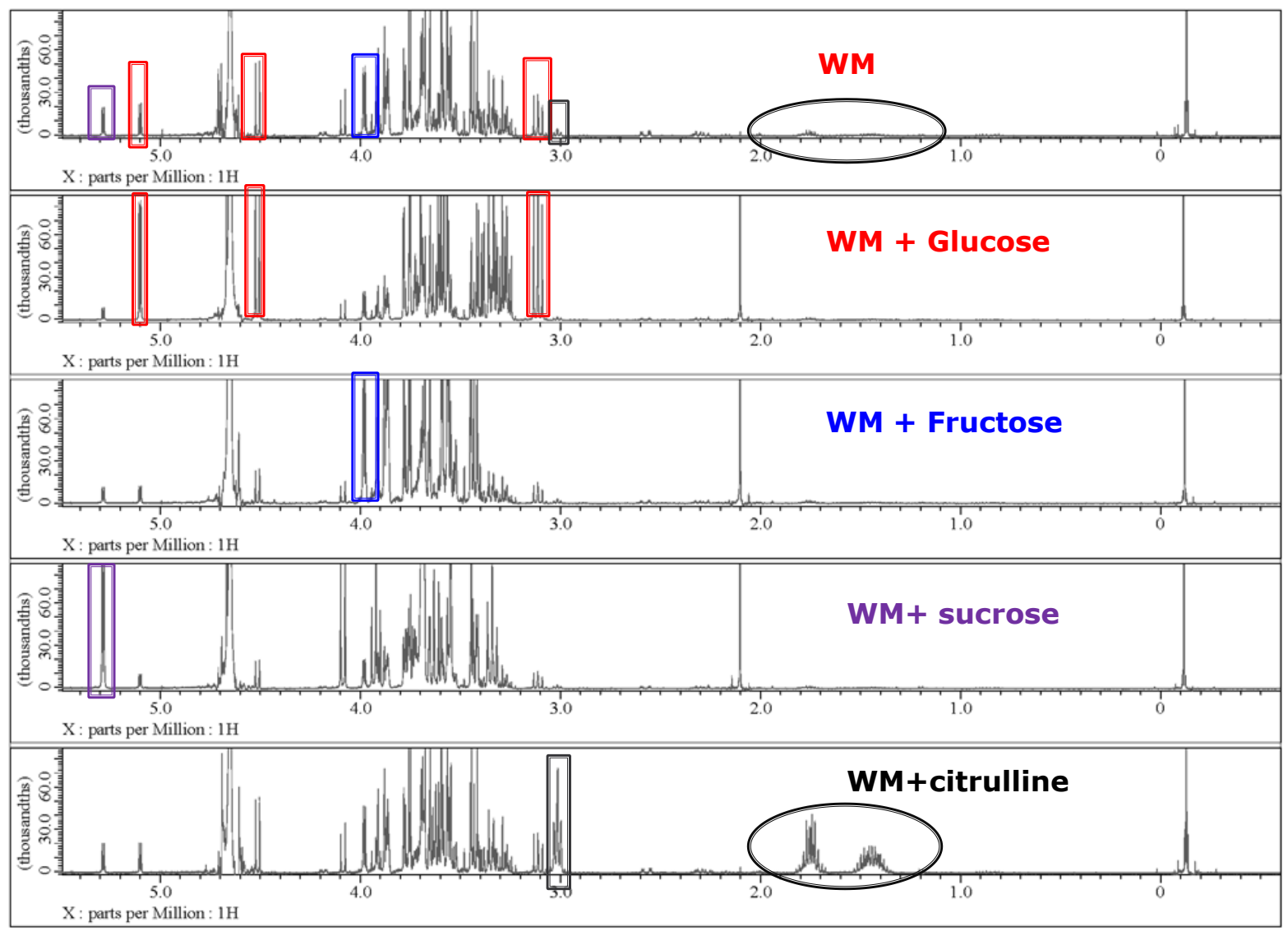

Fig. 2. Overlay ${ }^{1} \mathrm{H}$ NMR spectra of watermelon sample (WM) and watermelon sample spiked with the respective standards to see signal enhancement. The clearly visible enhanced signals are shown in the box and were used for quantification. 


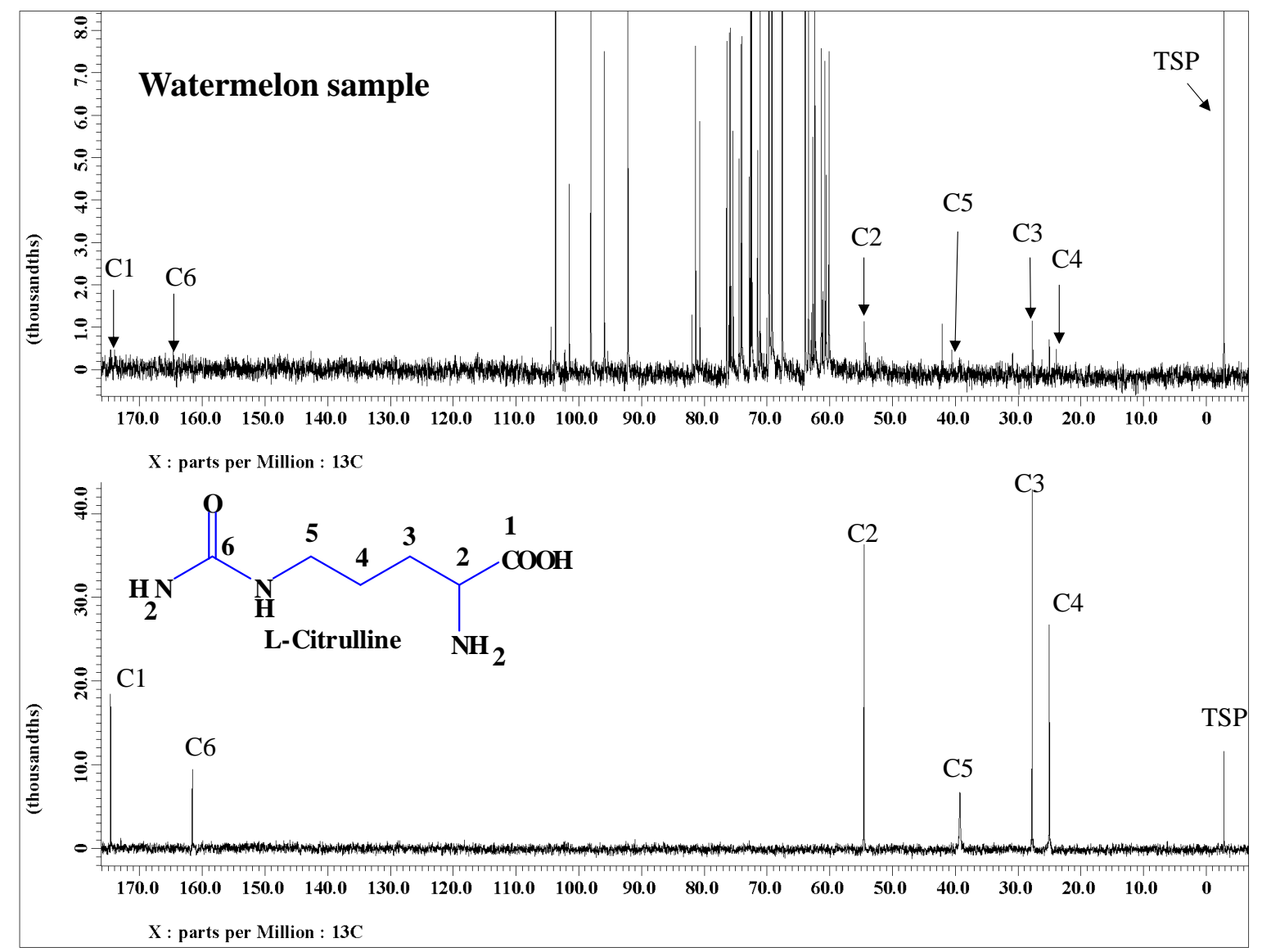

Fig. 3. ${ }^{13} \mathrm{C}$ decoupled spectra of watermelon sample and standard L-citrulline recorded in $\mathrm{D}_{2} \mathrm{O}$ at $100 \mathrm{MHz}$. L-citrulline carbon signals were assigned to respective signals in both spectra. $30 \mathrm{mg}$ of freeze-dried watermelon sample was extracted with $1 \mathrm{~mL}$ of $\mathrm{D}_{2} \mathrm{O}$ by vortexing for $1 \mathrm{~min}$, followed by sonication for $30 \mathrm{~min}$ and filtered through a 0.45 micron filter. For NMR, $525 \mu \mathrm{L}$ of the extract was transferred into 5-mm NMR tubes and an external glass stem coaxial insert (OD $2 \mathrm{~mm}$ ) containing $60 \mu \mathrm{L}$ of $0.012 \%$ TSP solution in $\mathrm{D}_{2} \mathrm{O}$ was inserted and spectra were recorded. 


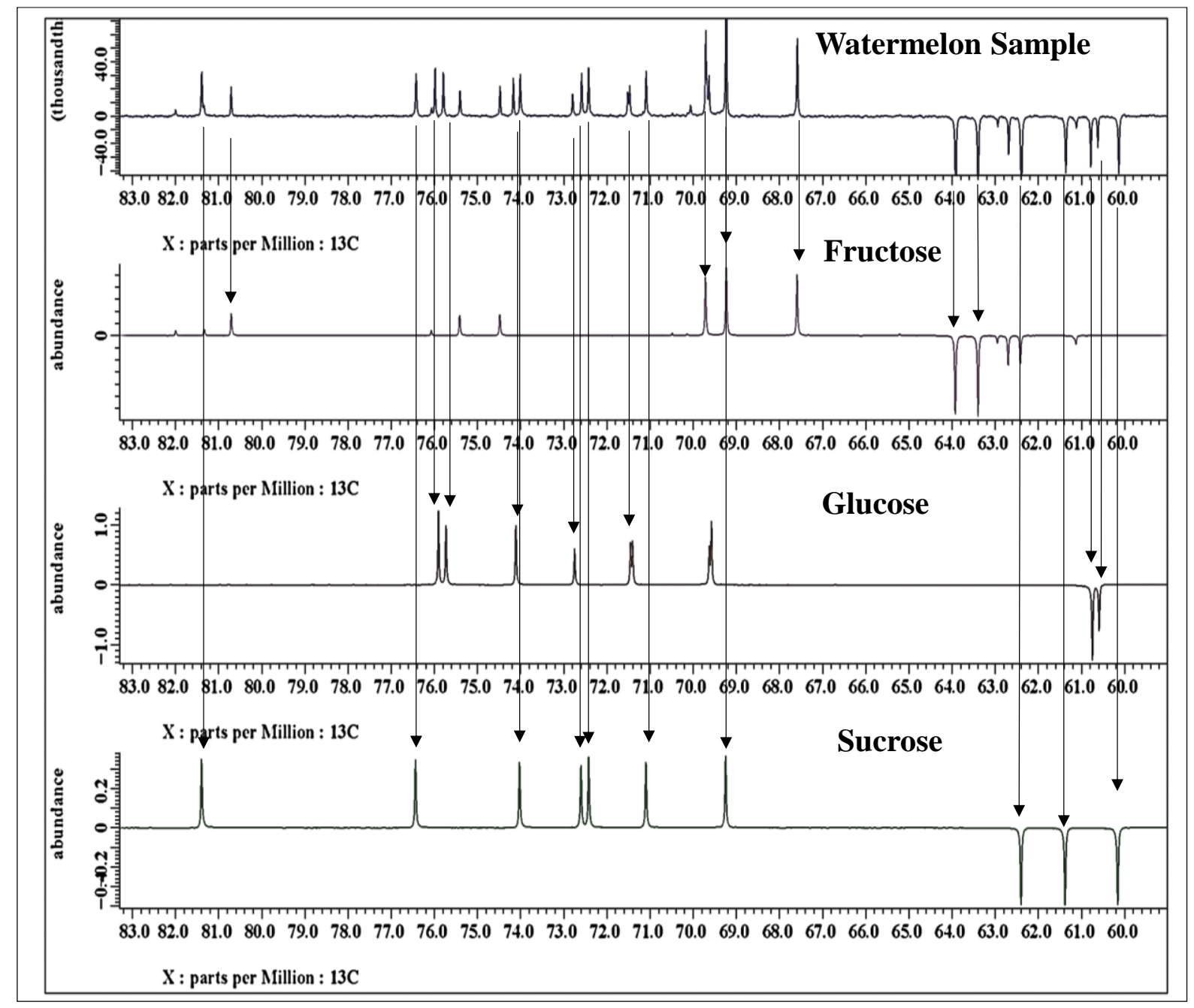

Fig. 4. A representative overlay ${ }^{13} \mathrm{C}$ DEPT-135 spectrum of a watermelon sample and standard sugars recorded at $100 \mathrm{MHz}$ in $\mathrm{D}_{2} \mathrm{O}$. All sugar signals from the sample were matched to standard sugar signals as shown by the arrows. 


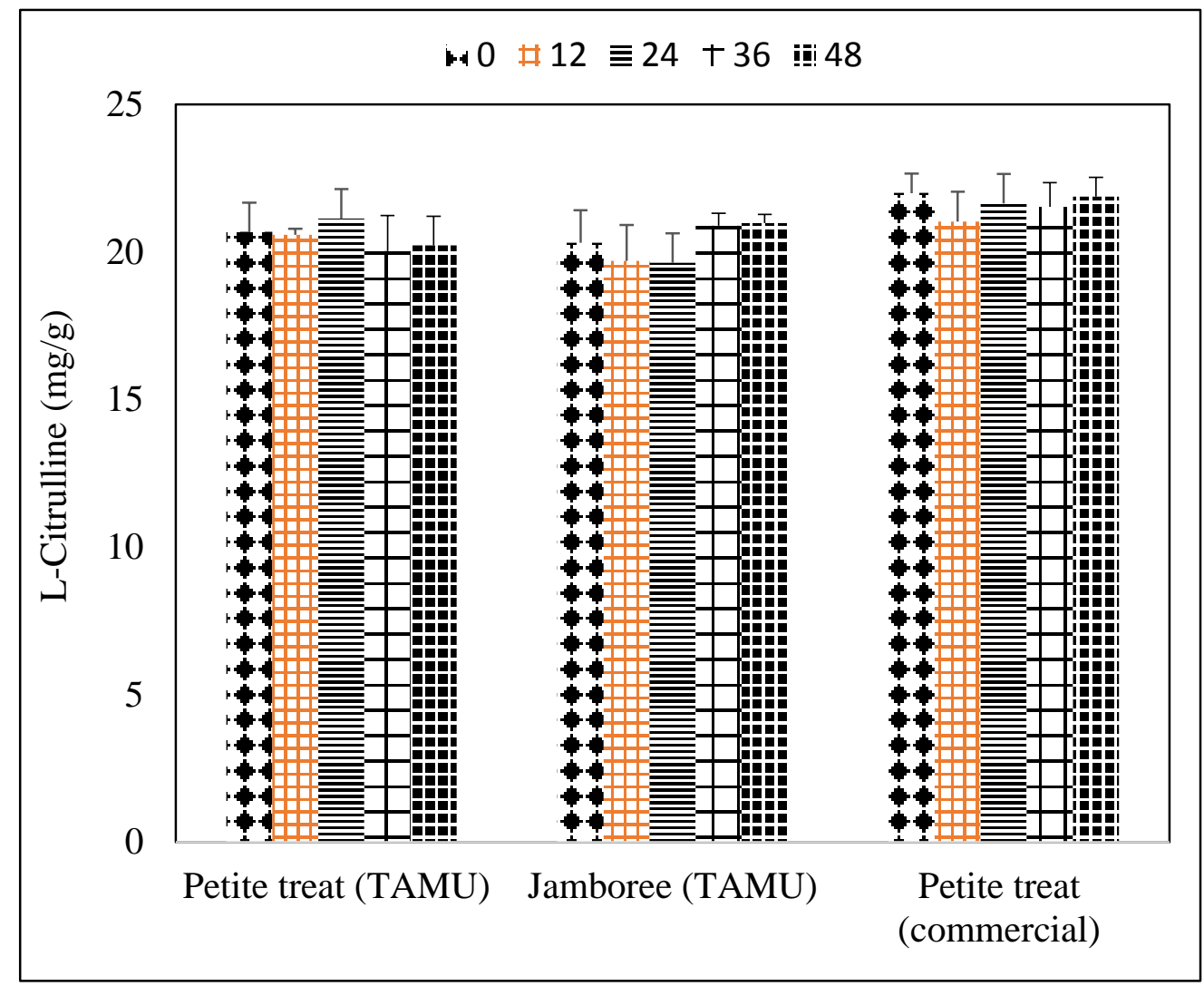

Fig. 5. Stability of L-citrulline present in three watermelon samples was measured by $q^{1} H N M R$ at different time intervals 

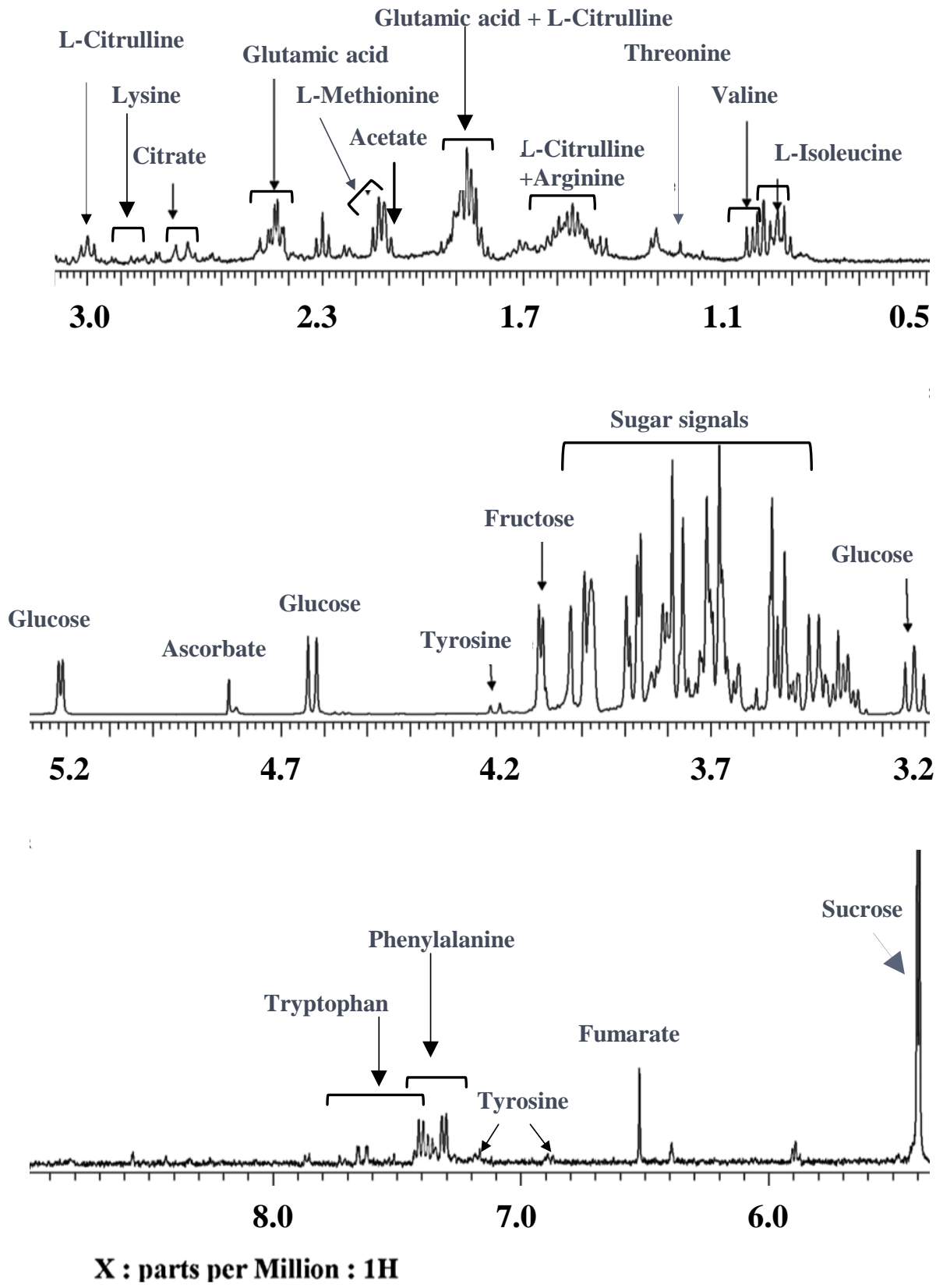

Fig. 6. A typical $400 \mathrm{MHz}{ }^{1} \mathrm{H}$ NMR spectrum of a watermelon sample extracted with $\mathrm{D}_{2} \mathrm{O}$ with expanded regions and annotations for all identified phytochemicals. 


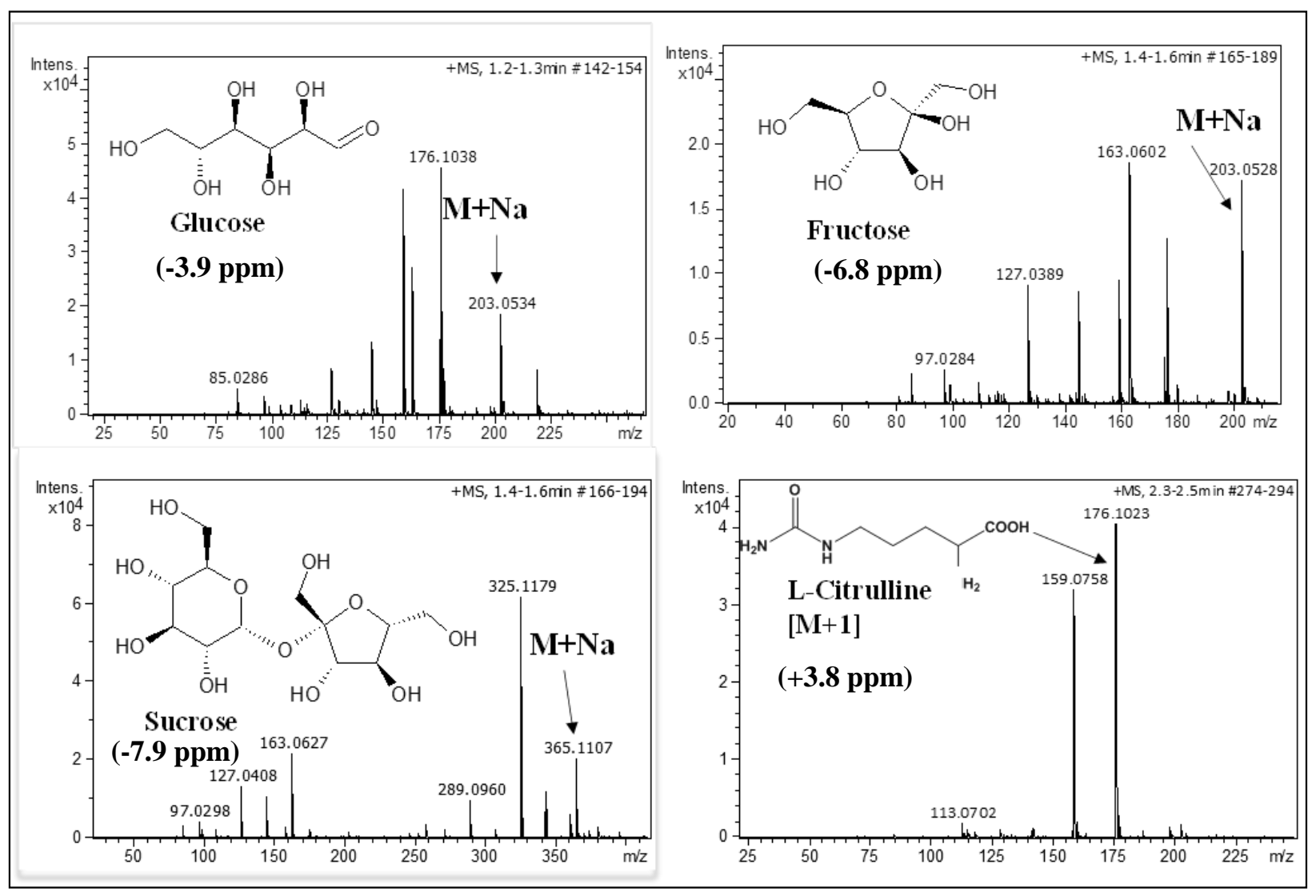

Fig. 7. Mass spectra of watermelon samples analyzed by HPLC with high-resolution time of flight by electrospray positive ionization mode. Mass spectra of four major compounds with their structures and mass error are shown. 
Table 1.

Assignment of characteristic proton signals to metabolites identified by ${ }^{1} \mathrm{H}$ NMR spectra obtained at $400 \mathrm{MHz}$ in $\mathrm{D}_{2} \mathrm{O}$

\begin{tabular}{|c|c|c|}
\hline Metabolite & $\begin{array}{c}\text { Proton signals from authenticated } \\
\text { standards }\end{array}$ & $\begin{array}{l}\text { Proton signal used for } \\
\text { quantitation / identification }\end{array}$ \\
\hline L-Isoleucine & $\begin{array}{l}3.55(\mathrm{~d}, 3.6 \mathrm{~Hz}), 1.89(\mathrm{~m}), 1.35(\mathrm{~m}), 1.15 \\
(\mathrm{~m}), 0.89(\mathrm{~d}, 7 \mathrm{~Hz}), 0.84(\mathrm{t}, 7.5 \mathrm{~Hz})\end{array}$ & $0.89(\mathrm{t}, 7 \mathrm{~Hz})$ \\
\hline Valine & $\begin{array}{l}3.48,(\mathrm{~d}, 4.4 \mathrm{~Hz}), 2.18(\mathrm{~m}), 0.96(\mathrm{~d}, \\
7.1 \mathrm{~Hz}), 0.86(\mathrm{~d}, 7.1 \mathrm{~Hz})\end{array}$ & $0.96(\mathrm{~d}, 7.1 \mathrm{~Hz})$ \\
\hline Threonine & $4.18(\mathrm{~m}), 3.51(\mathrm{~d}, 4.2 \mathrm{~Hz}), 1.28(\mathrm{~d}, 6.5 \mathrm{~Hz})$ & $1.28(\mathrm{~d}, 6.5 \mathrm{~Hz})$ \\
\hline L-Citrulline & $\begin{array}{l}3.68(\mathrm{t}, 1 \mathrm{H}), 3.05(\mathrm{t}, 2 \mathrm{H}), 1.81(\mathrm{~m}, 2 \mathrm{H}), \\
1.48(\mathrm{~m}, 2 \mathrm{H})\end{array}$ & $3.05(\mathrm{t}, 2 \mathrm{H})$ \\
\hline Arginine & $3.99(\mathrm{t}), 3.12(\mathrm{t}), 1.85(\mathrm{~m}), 1.66(\mathrm{~m})$ & $1.66(\mathrm{~m})$ \\
\hline Glutamic acid & $3.66(\mathrm{t}, 6.2 \mathrm{~Hz}), 2.35(\mathrm{~m}), 2.22(\mathrm{~m})$ & $2.35(\mathrm{~m})$ \\
\hline Acetate & $2.09(\mathrm{~s})$ & $2.09(\mathrm{~s})$ \\
\hline L-Methionine & $\begin{array}{l}3.75(\mathrm{t}, 6.3 \mathrm{~Hz}), 2.52(\mathrm{t}, 7.4), 2.07(\mathrm{~m}), \\
2.01(\mathrm{~s})\end{array}$ & $2.07(\mathrm{~m})$ \\
\hline Citrate & $\begin{array}{l}2.92(\mathrm{dd}, 1.9,15.8 \mathrm{~Hz}), 2.75(\mathrm{dd}, 1.95 \\
15.8 \mathrm{~Hz})\end{array}$ & $\begin{array}{l}2.92(\mathrm{dd}, 1.9,15.8 \mathrm{~Hz}), 2.75(\mathrm{dd}, \\
1.95,15.8 \mathrm{~Hz})\end{array}$ \\
\hline Lysine & $\begin{array}{l}3.65(\mathrm{t}), 2.92(\mathrm{bt}), 1.79(\mathrm{~m}), 1.6(\mathrm{~m}), \\
1.35(\mathrm{~m})\end{array}$ & $2.92(\mathrm{bt})$ \\
\hline Glucose & $\begin{array}{l}5.1(\mathrm{~d}), 4.51(\mathrm{~d}), 3.77(\mathrm{dd}), 3.6(\mathrm{dd}), 3.4 \\
(\mathrm{dd}), 3.3(\mathrm{dd}), 3.11(\mathrm{t})\end{array}$ & $5.1(\mathrm{~d}), 4.5(\mathrm{~d}), 3.11(\mathrm{t})$ \\
\hline Fructose & 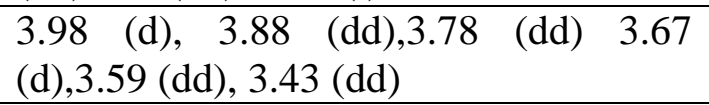 & $3.98(\mathrm{~d})$ \\
\hline Tyrosine & $\begin{array}{l}7.10(\mathrm{~d}, 8 \mathrm{~Hz}), 6.89(\mathrm{~d}, 8 \mathrm{~Hz}), 3.81(\mathrm{dd}, \\
5.3,7.7 \mathrm{~Hz}), 3.1(\mathrm{dd}, 15,5.3 \mathrm{~Hz}), 2.95 \\
(\mathrm{dd}, 14.9,7.7 \mathrm{~Hz})\end{array}$ & $7.10(\mathrm{~d}, 8 \mathrm{~Hz}), 6.89(\mathrm{~d}, 8 \mathrm{~Hz})$ \\
\hline Ascorbate & $4.85(\mathrm{~s}), 3.98(\mathrm{dd}) 3.65(\mathrm{~d})$ & $4.85(\mathrm{~s})$ \\
\hline Sucrose & $\begin{array}{l}5.3(\mathrm{~d}), 4.11(\mathrm{~d}), 3.92(\mathrm{t}), 3.7(\mathrm{~d}), 3.65 \\
(\mathrm{t}), 3.45(\mathrm{dd}), 3.35(\mathrm{t})\end{array}$ & $5.3(\mathrm{~d}), 4.11(\mathrm{~d})$ \\
\hline Fumarate & $6.75(\mathrm{~s})$ & $6.75(\mathrm{~s})$ \\
\hline Phenylalanine & $\begin{array}{l}7.42(\mathrm{~m}), 7.36(\mathrm{~m}), 7.32(\mathrm{~d}), 3.98(\mathrm{dd}), \\
3.19(\mathrm{~m})\end{array}$ & $7.42(\mathrm{~m}), 7.36(\mathrm{~m}), 7.32(\mathrm{~d})$ \\
\hline Tryptophan & $\begin{array}{l}7.72(\mathrm{~d}), 7.53(\mathrm{~d}), 7.31(\mathrm{~s}), 7.27(\mathrm{~m}) \\
7.19(\mathrm{~m}), 4.05(\mathrm{dd}), 3.47(\mathrm{dd}), 3.29(\mathrm{dd})\end{array}$ & $\begin{array}{l}7.72(\mathrm{~d}), 7.53(\mathrm{~d}), 7.31(\mathrm{~s}), 7.27 \\
(\mathrm{~m})\end{array}$ \\
\hline
\end{tabular}


Table 2.

Regression equations, LOD, and LOQ for L-citrulline and sugars

\begin{tabular}{|l|l|l|l|l|l|}
\hline Phytochemical & Regression equation & $\mathrm{R}^{2}$ & $\begin{array}{l}\text { Range } \\
(\mathrm{mg} / \mathrm{mL})\end{array}$ & $\begin{array}{l}\text { LOD } \\
(\mu \mathrm{g} / \mathrm{mL})\end{array}$ & $\begin{array}{l}\text { LOQ } \\
(\mu \mathrm{g} / \mathrm{mL})\end{array}$ \\
\hline L-Citrulline & $\mathrm{y}=8.4804 \mathrm{x}+0.0682$ & 0.99 & $0.071-1.14$ & 38 & 71 \\
\hline Glucose & $\mathrm{y}=7.152 \mathrm{x}+0.2059$ & 0.97 & $0.12-1.92$ & 94 & 120 \\
\hline Fructose & $\mathrm{y}=5.9875 \mathrm{x}-0.0495$ & 0.99 & $0.12-1.97$ & 64 & 120 \\
\hline Sucrose & $\mathrm{y}=5.5662 \mathrm{x}+0.1691$ & 0.99 & $0.11-1.76$ & 59 & 120 \\
\hline
\end{tabular}

$\mathrm{x}$ : concentration of phytochemical

y: Integral area of phytochemical obtained by qNMR to internal standard (IS) TSP-d 4 
Table 3.

Recovery of L-citrulline determined by qHNMR

\begin{tabular}{|c|c|c|c|c|c|}
\hline \multirow{2}{*}{$\begin{array}{l}\text { Spiked } \\
\text { levels }\end{array}$} & $\begin{array}{c}\text { L-Citrulline } \\
\text { spiked }(\mu \mathrm{g})\end{array}$ & $\begin{array}{c}\text { L-Citrulline } \\
\text { present in } \\
\text { watermelon } \\
\text { samples }(\mu \mathrm{g})\end{array}$ & $\begin{array}{c}\text { Expected } \\
\text { L- } \\
\text { Citrulline }\end{array}$ & $\begin{array}{c}\text { Actual L- } \\
\text { Citrulline } \\
\text { levels from } \\
\text { qNMR }\end{array}$ & \% Recovery \\
\hline \multirow{3}{*}{1} & 500 & 240.00 & 740.00 & 789.35 & 106.67 \\
\cline { 2 - 6 } & 500 & 240.00 & 740.00 & 808.04 & 109.20 \\
\hline \multirow{2}{*}{2} & 1000 & 240.00 & 1240.00 & 1250.42 & 100.84 \\
\cline { 2 - 6 } & 1000 & 240.00 & 1240.00 & 1335.51 & 107.70 \\
\cline { 2 - 6 } 3 & 2000 & 240.00 & 2240.00 & 2278.47 & 101.72 \\
\hline
\end{tabular}


Table 4.

Comparison of L-Citrulline levels $(\mathrm{mg} / \mathrm{g}) *$ in different varieties of watermelons measured by qNMR and HPLC

\begin{tabular}{|c|c|c|c|c|}
\hline & Varieties & $\begin{array}{c}\text { Number of } \\
\text { samples }\end{array}$ & NMR** & HPLC** \\
\hline \multirow{7}{*}{ Small Melons } & \multirow{4}{*}{$\begin{array}{c}\text { Petite treat } \\
\text { (TAMU) }\end{array}$} & 1 & $12.30 \pm 1.67^{\mathrm{a}}$ & $14.39 \pm 1.89^{\mathrm{a}}$ \\
\hline & & 2 & $14.41 \pm 1.11^{\mathrm{a}}$ & $15.42 \pm 1.07^{\mathrm{a}}$ \\
\hline & & 3 & $12.42 \pm 1.26^{\mathrm{a}}$ & $14.90 \pm 0.36^{a}$ \\
\hline & & 4 & $17.18 \pm 1.49^{b}$ & $17.74 \pm 1.07^{b}$ \\
\hline & \multirow{3}{*}{$\begin{array}{c}\text { Petite treat } \\
\text { (Commercial) }\end{array}$} & 1 & $20.35 \pm 2.84^{\mathrm{b}}$ & $19.24 \pm 0.65^{\mathrm{b}}$ \\
\hline & & 2 & $21.45 \pm 1.84^{b}$ & $22.47 \pm 0.37^{b}$ \\
\hline & & 3 & $24.22 \pm 1.07^{b}$ & $24.37 \pm 1.09^{b}$ \\
\hline \multirow{7}{*}{ Big melons } & \multirow{3}{*}{$\begin{array}{c}\text { Jamboree } \\
\text { (TAMU) }\end{array}$} & 1 & $17.23 \pm 1.52^{\mathrm{a}}$ & $19.23 \pm 1.29^{\mathrm{a}}$ \\
\hline & & 2 & $17.78 \pm 2.02^{\mathrm{a}}$ & $17.98 \pm 0.8^{\mathrm{a}}$ \\
\hline & & 3 & $15.52 \pm 0.66^{\mathrm{a}}$ & $18.89 \pm 0.24^{\mathrm{a}}$ \\
\hline & \multirow{4}{*}{$\begin{array}{c}\text { Petite treat } \\
\text { (Commercial) }\end{array}$} & 1 & $20.84 \pm 1.93^{b}$ & $20.01 \pm 0.72^{b}$ \\
\hline & & 2 & $17.21 \pm 1.21^{\mathrm{a}}$ & $16.98 \pm 0.21^{\mathrm{a}}$ \\
\hline & & 3 & $22.60 \pm 1.65^{b}$ & $22.37 \pm 1.94^{\mathrm{b}}$ \\
\hline & & 4 & $20.48 \pm 0.63^{b}$ & $17.09 \pm 1.89^{\mathrm{a}}$ \\
\hline
\end{tabular}

*: All results presented as mean \pm SE from three independent experiments.

** No significant differences were observed between qNMR and HPLC methods

a: No significant differences were observed among small or big melons within the same column

b: Significant differences were observed among small or big melons within the same column 
Table 5. Comparison of Sugars $(\mathrm{mg} / \mathrm{g}) *$ in different varieties of watermelons measured by qNMR and HPLC

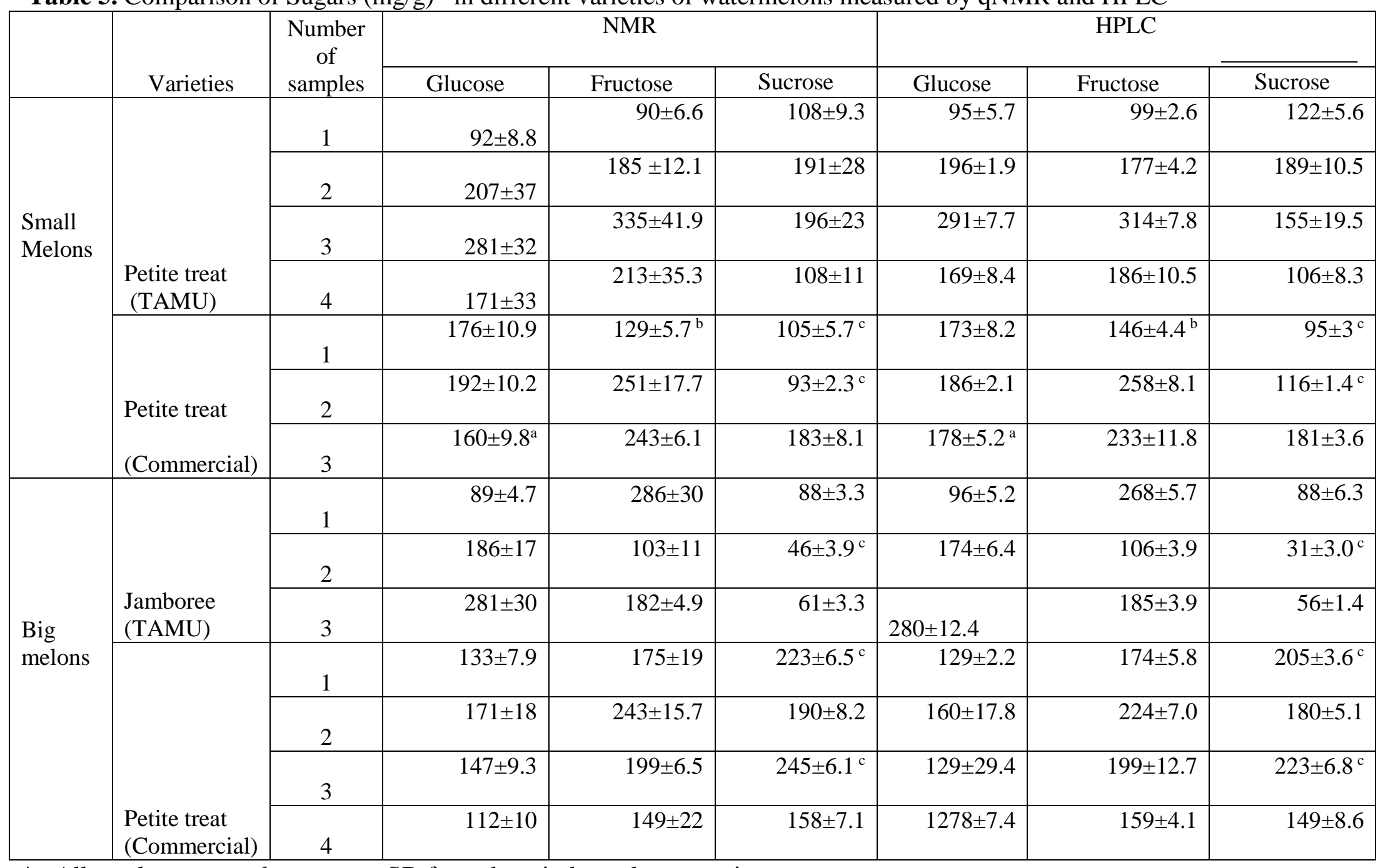

*: All results presented as mean \pm SD from three independent experiments.

a: Significant differences were observed in glucose levels in ${ }^{1} \mathrm{H}$ qNMR and HPLC

${ }^{b}$ : Significant differences were observed in fructose levels in ${ }^{1} \mathrm{H}$ qNMR and HPLC

c: Significant differences were observed in sucrose levels in ${ }^{1} \mathrm{H}$ qNMR and HPLC 


\section{Graphical Abstract}

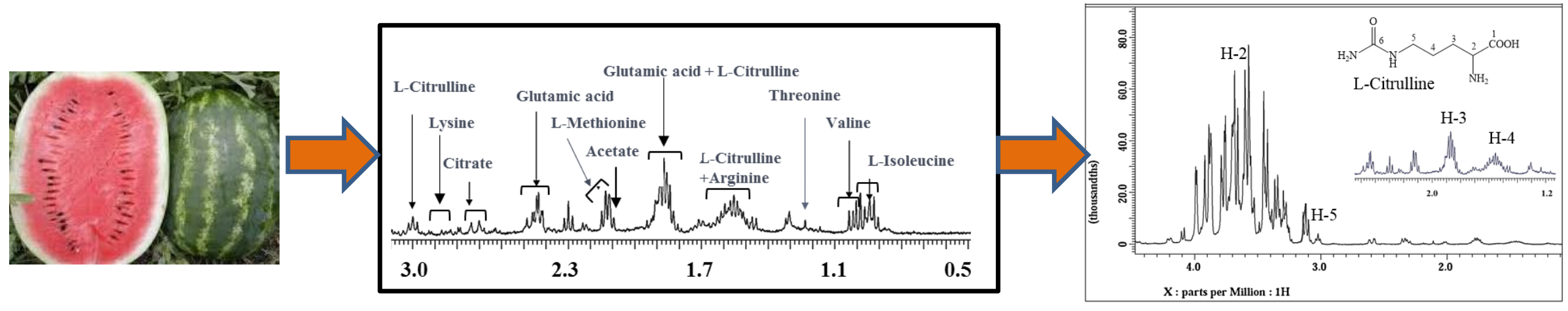

Watermelon

Identification of metabolites using ${ }^{1} \mathrm{HNMR}$

Quantification of phytochemicals 